\title{
Ultrasound-guided core-needle biopsy of breast lesions
}

\author{
Luis Apesteguía $\cdot$ Luis Javier Pina
}

Received: 1 September 2010 /Revised: 24 December 2010 /Accepted: 17 March 2011 /Published online: 15 April 2011

(C) European Society of Radiology 2011

\begin{abstract}
Objective To review the role of ultrasound-guided coreneedle biopsy (CNB) in the management of breast lesions. Methods Review of the most relevant literature on this topic.

Results This technique shows a high sensitivity value of about $97.5 \%$ and it offers many advantages over other imaging techniques to guide a biopsy: non-ionising radiation, low cost, full control of the needle in real time, accessibility in difficult locations, multidirectional punctures and excellent comfort for patients and radiologists. All of these advantages have made this technique the most widespread used to perform a biopsy for a suspicious breast lesion. The most important limitation is the failure to perform a biopsy for lesions that are not seen on ultrasound. An adequate radiological-pathological correlation is necessary to minimise the false-negative results.

Conclusion Ultrasound-guided CNB has proven to be a reliable technique for performing a biopsy for breast lesions that can be clearly seen on ultrasound.
\end{abstract}

Keywords Core needle · Biopsy · Ultrasound guided · Breast

\footnotetext{
L. Apesteguía

Department of Radiology, Hospital Virgen del Camino,

C/ Irunlarrea 4,

31008 Pamplona, Spain

e-mail: lapestec@cfnavarra.es

L. J. Pina $(\bowtie)$

Department of Radiology, Clínica Universidad de Navarra,

C/ PIO XII 36,

31008 Pamplona, Spain

e-mail: ljpina@unav.es
}

\section{Introduction}

Nowadays, percutaneous imaging-guided breast biopsy is a reliable alternative to surgical biopsy for a histological diagnosis [1-5]. Percutaneous biopsy is less invasive than surgery, can be performed quickly, does not deform the breast, causes minimal scarring, complications (haematoma and infection) are infrequently found (less than one case in $1,000)$, fewer surgeries are needed for patients who undergo percutaneous biopsies and therefore the cost of diagnosis is lower [1-5].

There are two main objectives of percutaneous biopsy techniques: first, achieving the maximum degree of accuracy and second, offering as much information as possible about the tumour (type, grade, invasion, hormonal receptors, HER-2 NEU, etc.). To achieve these objectives, the percutaneous biopsy devices have evolved, from fineneedle aspiration cytology towards core-needle biopsy (CNB) and later vacuum-assisted biopsy (VAB) [1]. Nowadays, ultrasound-guided core needle breast biopsy has become the first choice for performing a percutaneous biopsy for most lesions seen on ultrasound [1, 6-9]. Virtually any breast lesion that is clearly seen on ultrasound can be sampled under ultrasound guidance [6]. Many surgical biopsies that had to be carried out in the past, because of suspicious radiological findings, are nowadays unnecessary due to the extensive use of ultrasound NCB. In addition, surgical specimens removed after a previously proven malignant result are usually more adequate for the tumour size. Consequently, the number of surgical procedures has also been reduced for malignant lesions. Thus, the number of surgical procedures has drastically decreased both for benign and malignant lesions, thanks to the 
extensive use of ultrasound CNB and the other methods of percutaneous biopsy.

The technique was first described by Parker and coworkers in the early 1990s, and nowadays ultrasound CNB has become the first choice for performing most breast biopsies $[2,4,5,9]$.

\section{Advantages and limitations of ultrasound NCB}

The numerous advantages of ultrasound guidance over stereotactic and MR guidance have been key in explaining the widespread use of this technique. Noteworthy among these advantages are:

- Ultrasound involves non-ionising radiation.

- Full control of the needle position in real time. Neither stereotactic guidance nor MR guidance offers this advantage.

- Ultrasound equipment is cheaper and more readily available than stereotactic or MR units.

- Accessibility of difficult places, such as the axilla or near the nipple. These are limitations for stereotactic or MR guidance.

- Multiple lesions (unilateral or bilateral) can be safely biopsied in one session, usually more quickly than with other imaging techniques.

- The breast is not compressed.

- Excellent comfort for patients and radiologists, although stereotactic prone tables are also comfortable for both.

- Local anaesthesia and haematoma do not hide the lesion (non-calcified masses can be obscured with use of stereotactic equipment). However, bubbles injected with the local anaesthesia can obscure the lesion.

- It is a cost-effective technique: Liberman et al. [8] found that ultrasound CNB yielded a $56 \%$ decrease in the cost of diagnosis. For masses amenable to either stereotactic or ultrasound guidance, cost savings are greater if the biopsy is performed under ultrasound guidance [8]. According to Schueller et al. [10], overall cost savings for ultrasound CNB over surgical biopsy were 977 euros [10].

The main disadvantage of ultrasound $\mathrm{CNB}$ is the limitation of performing a biopsy for lesions not seen on ultrasound. Most clustered microcalcifications, especially if they are not inside a mass, cannot be identified on ultrasound. However, high-resolution transducers can demonstrate some clustered microcalcifications even in the absence of a mass.

Although most ultrasound CNB procedures are easy to perform, in some special situations (deeply located lesions, patients with implants, axillary lesions, etc.) a high level of experience is needed to get reliable results.

\section{Current indications and contraindications}

All lesions classified as BI-RADS 4 and 5, clearly visible on ultrasound, are amenable to ultrasound CNB [6]. This technique can also be used for some BI-RADS 3 lesions under certain circumstances: genetic or family risk, medical or social difficulties for follow-up, pregnancy, extreme anxiety and others, including the patient's decision.

Ultrasound CNB can be difficult in patients with severe psychiatric disorders, which makes them impossible to collaborate on, and is contraindicated in some cases of severe blood dyscrasia. However, there are no statistically significant differences in haematoma formation between patients taking anticoagulant therapy daily and non-treated patients [11]. Thus, it is not necessary to stop that therapy to perform an ultrasound CNB. Expert radiologists can perform biopsies of very deep lesions located close to the pectoral muscle in large breasts. Obtaining a biopsy in some patients with silicone implants can be also contraindicated.

Palpable lesions can be safely biopsied under ultrasound guidance. Although surgeons have been using CNB guided by palpation for a long time [12], the accuracy is increased with ultrasound guidance [13].

As well as diagnostic objectives, ultrasound guidance allows us to perform other interesting therapeutic procedures such as evacuation of liquid or semi-solid collections and placement of markers or coils for neoadjuvant chemotherapy. More recently, ultrasound guidance has been useful for tumour ablation using radiofrequency, cryoablation, laser therapy or focused ultrasound [14-16].

\section{Technical procedure}

There is a wide spectrum of core-needle devices that can be used under ultrasound guidance (Fig. 1). The thickness of

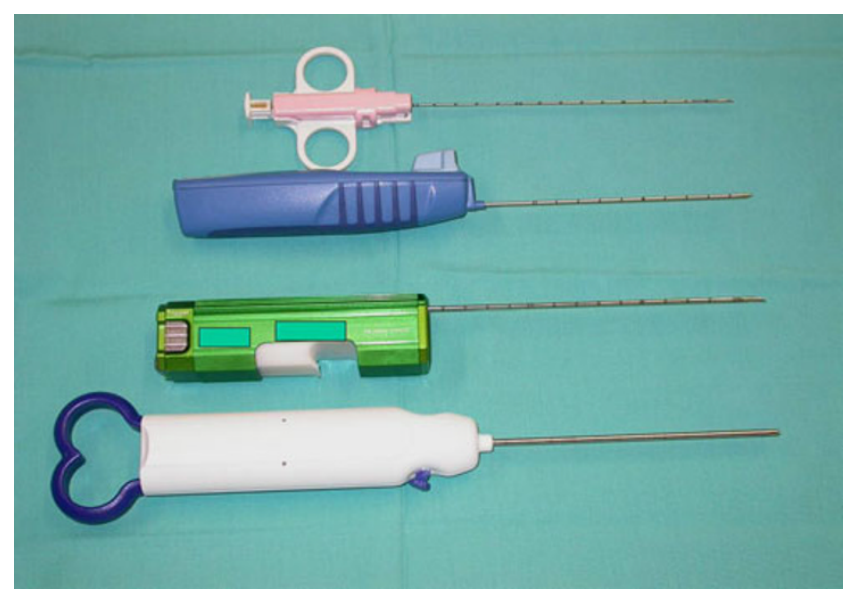

Fig. 1 A small sample of the great variety of biopsy devices that can be used under ultrasound guidance 
Fig. 2 These pictures illustrate how the ultrasound $\mathrm{CNB}$ procedure is performed. a Local anaesthesia is injected, $\mathbf{b}$ a small incision is required and $\mathbf{c}$ the biopsy device is guided by ultrasound
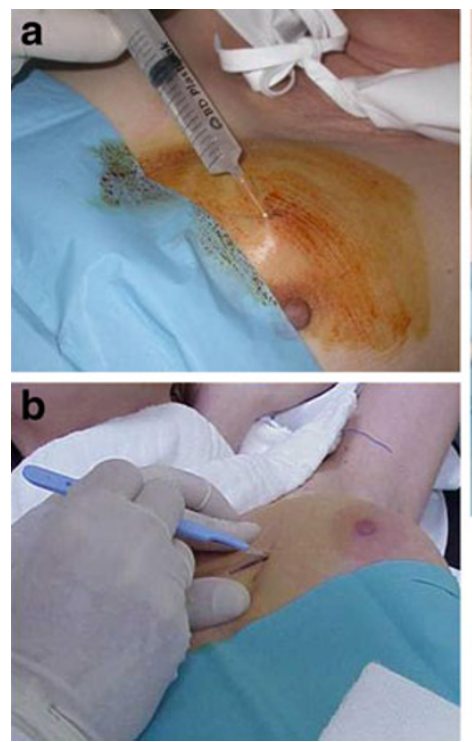

the needles can be selected, varying from 18- to 8-gauge; however, 14-gauge conventional Tru-cut devices have been the most commonly used [6]. Nowadays there is a trend towards using 10- to 11-gauge vacuum-assisted devices.

It is very important to correlate mammography, ultrasound and MRI findings, in order to carry out the puncture using the most suitable method of guidance. Sometimes it is necessary to perform several biopsies in the same patient using different techniques of imaging guidance (i.e. microcalcifications under stereotactic guidance and a mass, only visible on ultrasound, under ultrasound guidance). Metallic markers can be placed superficially on the skin close to the lesion or inside the lesion to correlate ultrasound and mammography findings.
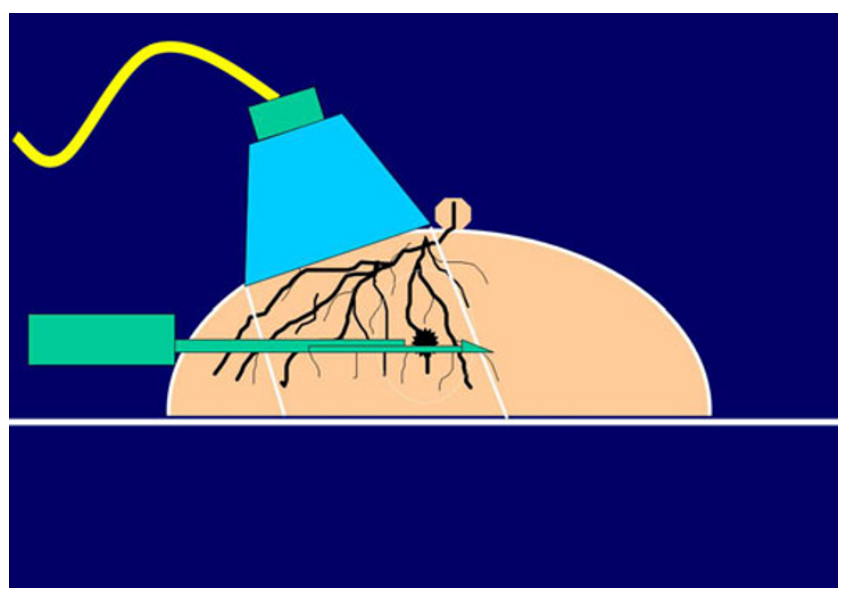

Fig. 3 The approach to the lesion should be as parallel to the chest wall as possible to avoid pneumothorax. Moreover the transducer should be orientated parallel to the needle in order to facilitate the needle visualisation
The use of high-frequency (10- to 12-MHz) probes, adjustments in the dynamic range and postprocessing grey scales, as well as correct focus, are important to improve the visibility of breast lesions.

The patients should have a complete, thorough level of information about the technique, indications, contraindications, complications and alternative possibilities; therefore, obtaining informed consent is mandatory. Local anaesthesia must be injected superficially and also as deeply as necessary, under sterile conditions. This anaesthesia does not mask the lesion and sometimes can help us to move it to another, more accessible place, deeper or more superficial. However, bubbles mixed with the anaesthesia can mask the lesion; thus, they must be avoided.

After localising the lesion with ultrasound, the procedure is performed in an outpatient setting, using the free-hand technique: one hand holds the probe and the other hand holds the needle (Fig. 2). One of the main advantages of ultrasoundguided CNB is the full control of the needle position in real time, allowing for corrections in the needle direction.

As a general rule, the shortest route from the skin to the lesion should be used. A vertical approach would be the best, but it is not possible under ultrasound guidance. However, an oblique approach, as parallel to the chest wall as possible, should be used (Fig. 3). This is the way to avoid pneumothorax, the worst complication of this technique. This approach also enables the best visualisation of the needle, because even large-gauge needles are difficult to visualise if a steep angle is used because of less reflective echoes. However, when the needle is parallel to the probe, the number of needle-generated reflected echoes that are perpendicular to the ultrasound beam is maximised, so the needle can be identified. This horizontal approach can be used to perform a biopsy for cutaneous lesions (Fig. 4). 
Fig. 4 An ultrasound $\mathrm{CNB}$ is performed in this cutaneous metastasis (arrows). Note the horizontal approach needed in this case
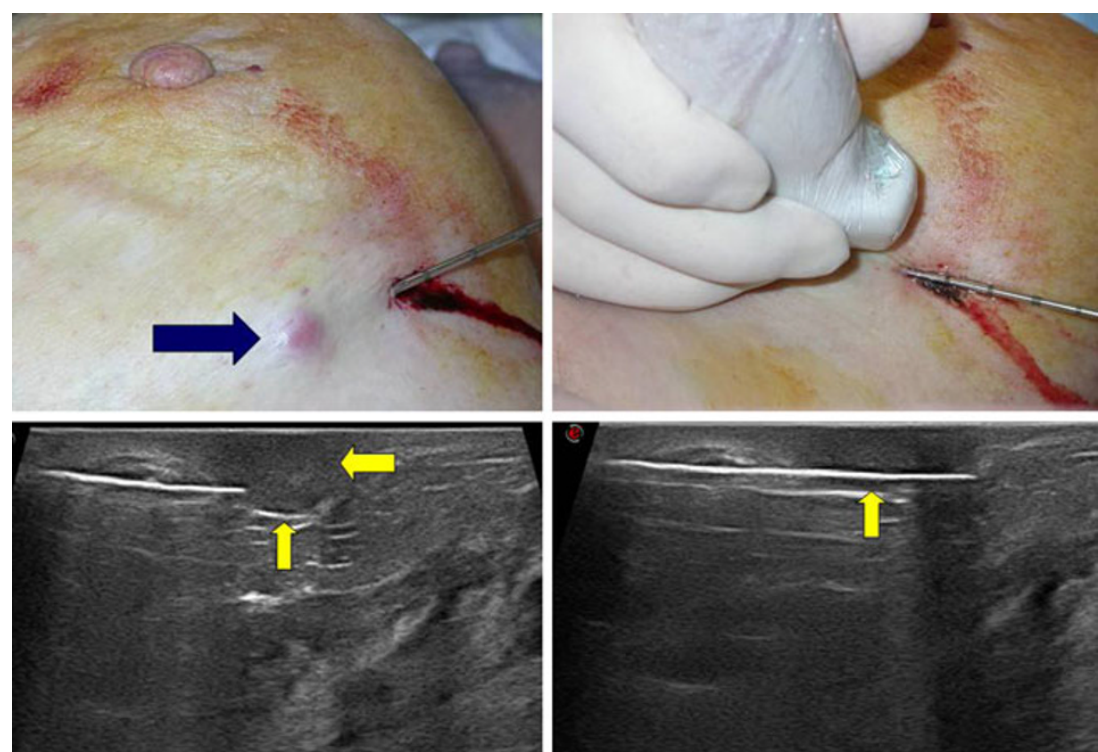

It is useful to move the patient to lateral decubitus positions, especially in the case of deeply located lesions or peripheral masses. If possible, an approach through fat is preferable, because the puncture is easier (the fat is soft and the needle can be easily guided; Fig. 5).

It is important to insert the tip of the needle inside the mass, because there is a dead space behind the tip. If the tip is not inserted, then part of the specimen will not belong to the lesion but to the perilesional tissue, and there is a risk of lancing the lesion, especially if it is very hard. Necrotic tissue inside the lesion should not be targeted. Pre-fire and post-fire images are important to ensure the correct position of the needle and to rule out the occurrence of complications (Fig. 6).

In the case of very dense breasts, the punction can be difficult. There are some tricks that can be used:

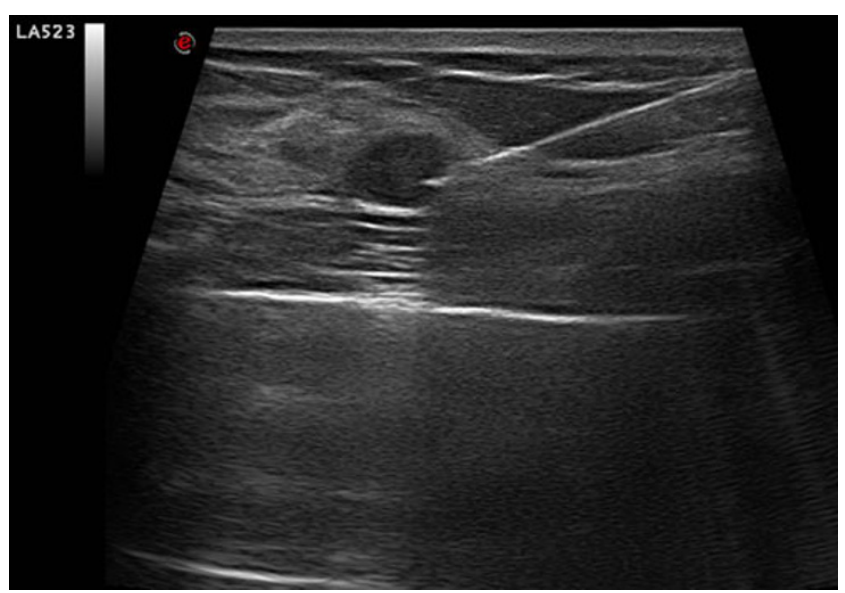

Fig. 5 A puncture through a fat lobule is easier than through fibrous dense tissue
- Coaxial technique: once the coaxial needle is inserted in the lesion, the inner trocar can be removed and replaced by the biopsy needle [6].

- A 16-gauge needle instead of a 14-gauge one. The smaller diameter, the lower friction with the surrounding tissue. The punction is easier and the strength of the shot is greater.

- Stronger devices, such as vacuum-assisted devices.

- Devices with diamond-shaped needle tips, because they transverse the fibrous tissue better than conventional needles (Fig. 7).

In the case of deeply located lesions there is a need to use a parallel approach to the chest wall, so that this structure is not penetrated and pneumothorax is avoided. Other tricks that can be used include:

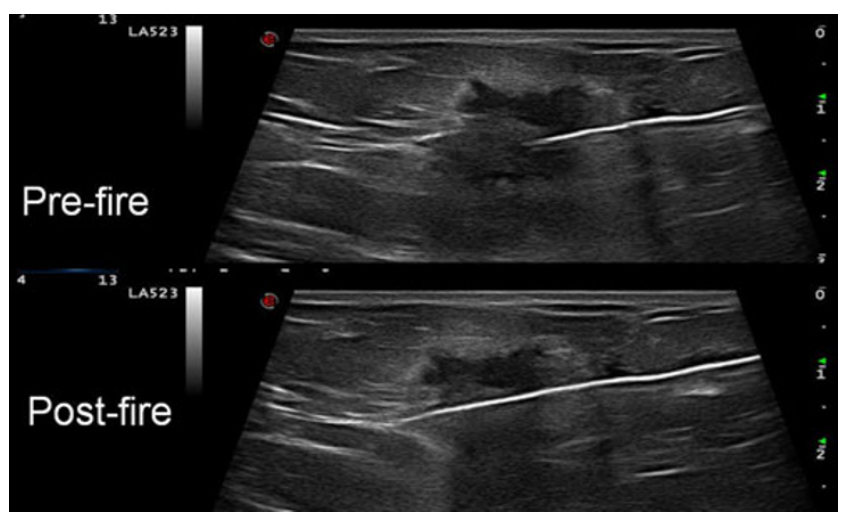

Fig. 6 One of the main advantages of ultrasound CNB is the full control of the needle direction in real time. Pre-fire and post-fire images are useful to ensure the correct position of the needle 


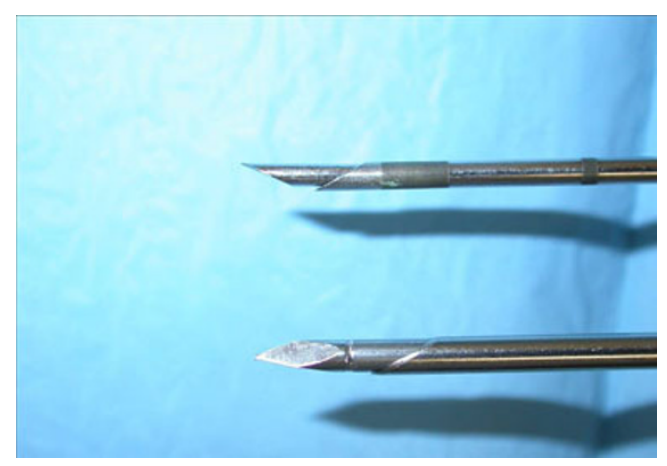

Fig. 7 Diamond-shaped needle tips are better than conventional ones to traverse the fibrous tissue

- The needle can be used as a lever: the entry of the needle has to be located about $2 \mathrm{~cm}$ from the edge of the transducer and the lesion is manually lifted away from the chest wall [6].

- Local anaesthesia can be used to move the lesion to a more convenient place, especially if it is injected deep to the lesion (Fig. 8).

The macroscopic evaluation of the specimens is also important, because it can give additional information about their quality: colour, consistency and grade of immersion of the cylinders in formaldehyde can be useful criteria for knowing their suitability for diagnosis. Intact, white or brown samples that quickly sink are considered more representative and are consequently preferred to fragmented, floating yellow ones, normally containing only adipose tissue [17]. This is the first index of correlation; of course it is not conclusive, but only orientative (Fig. 9). If the biopsied lesion is a cluster of microcalcifications, a specimen radiograph is mandatory to confirm the presence of microcalcifications (Fig. 10).
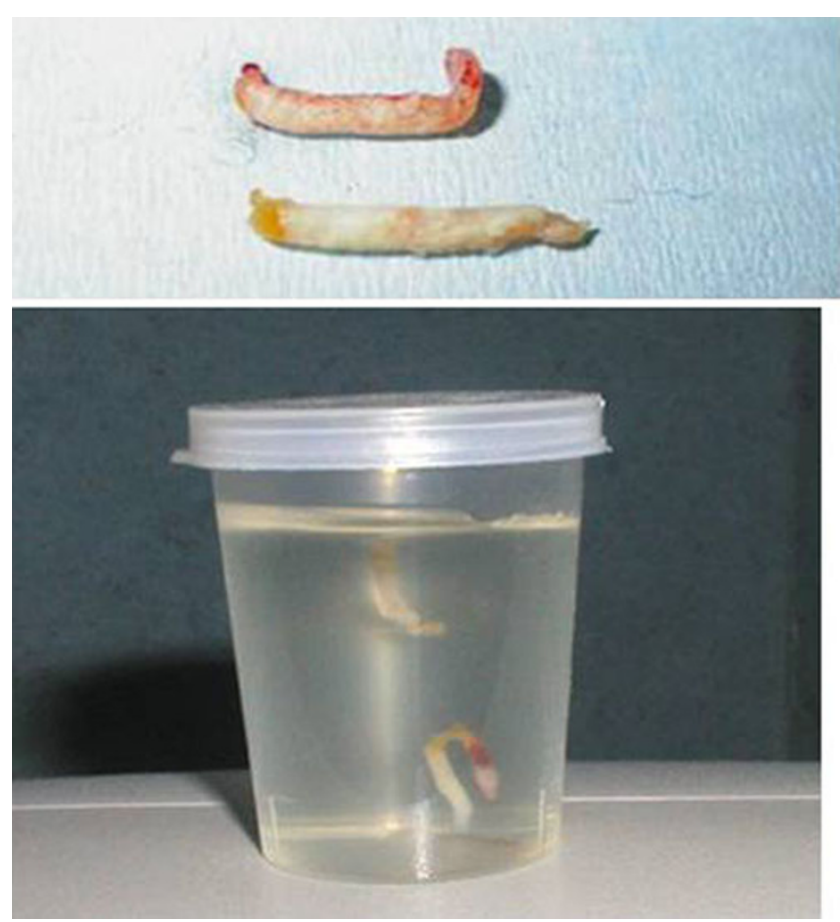

Fig. 9 White specimens that sink are usually more representative than floating yellow specimens

Four specimens may be enough for a reliable diagnosis, according to Fishman et al. [17]. However, other authors find a diagnosis with only two specimens to be reliable [18].

Vacuum-assisted biopsy devices under ultrasound guidance have been used as an alternative to conventional ultrasound $\mathrm{CNB}$. When VAB is performed, more specimens are removed [19].

However, Philpotts et al. [20] compared the two techniques (181 CNB procedures vs $100 \mathrm{VAB}$ procedures) and found no significant differences in false-negative
Fig. 8 The injection of local anaesthesia below the lesion can move it to a more superficial position

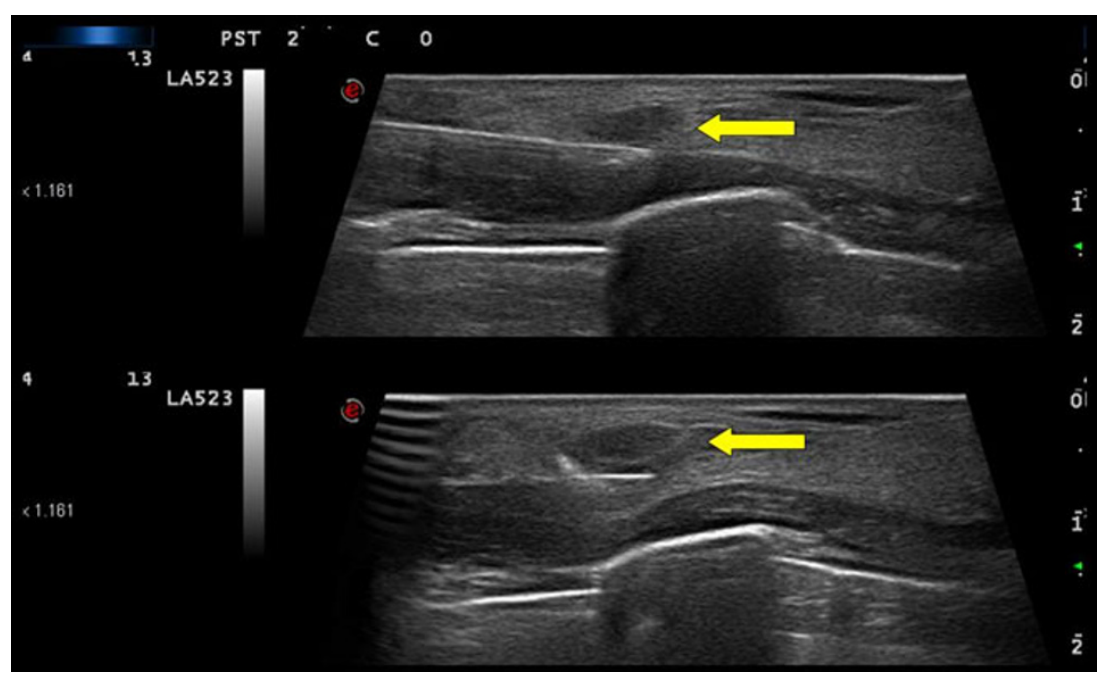




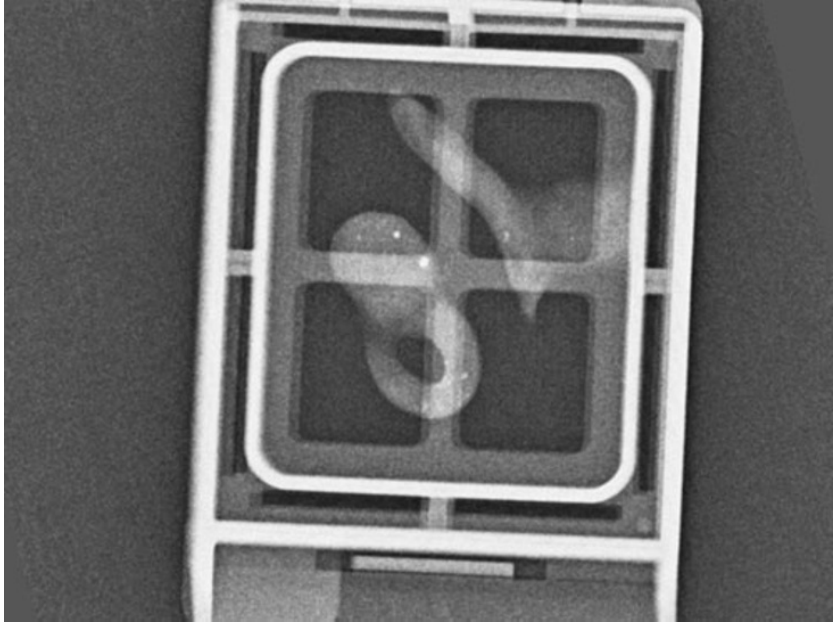

Fig. 10 Specimen radiograph showing microcalcifications. The radiograph was taken in a digital mammographic unit (Inspiration, Siemens, Erlangen, Germany) at $23 \mathrm{KV}$ and $9 \mathrm{mAs}$. The cylinders were collected into a plastic cassette

results, underestimation and complications. The reason for such a result is probably the homogeneity of most ultrasound-detected lesions (a small specimen is representative of the whole lesion) and the low frequency of borderline results (such as atypical ductal hyperplasia and others, which are usually associated with microcalcifications and are not seen on ultrasound).

However, the number of samples should be greater for those lesions with complex radiological features. In these cases, for example parenchymal distortions or asymmetric densities, more samples and/or thicker needles are recommended. The first cylinders are the most important ones, because later the suspicious lesion can be masked by variable degrees of bleeding.

\section{Results}

After the initial results by Parker and co-workers, with a $100 \%$ correlation with surgical results for 49 excised masses and no additional cancers in the remaining 132 cases, all the published series have shown excellent results (Table 1) [7-10, 17, 21-26]. Sensitivity of ultrasoundguided CNB is about $97.5 \%$, which makes this technique a very good choice for performing a breast biopsy. In published series $10 \%$ of lesions required repeat biopsy, $17 \%$ of which had malignancy [27]. Most of the cancers that were not initially diagnosed were biopsied again after new evaluation. Radiological-pathological correlation is the clue to diagnosing those missed cancers. Therefore, the correlation between radiological and histological findings is very important.

\section{Radiological-pathological correlation}

Despite performing an optimised biopsy procedure, a falsenegative result can occur. In the case of microcalcifications, the specimen radiograph is very useful for confirming them in the removed tissue. However, the specimen radiograph does not give additional information on non-calcified lesions. Post-biopsy mammography usually shows no substantial alteration in the target lesion with conventional 14-gauge needles. Therefore, the radiological-histological correlation is crucial to avoid false-negative results.

Five situations of radiological-histological correlation can occur [28]:

- Concordant malignancy: a lesion that is radiologically suspicious for malignancy (BI-RADS category 4 or 5) is histologically diagnosed as malignant after core
Table 1 Results for breast ultrasound-guided CNB series

\begin{tabular}{llll}
\hline Authors & Year & Total number of cancers & Cancers diagnosed (sensitivity) \\
\hline Parker et al. [9] & 1993 & 34 & $34(100 \%)$ \\
Liberman et al. [8] & 1998 & 58 & $56(97 \%)$ \\
Schulz-Wendtland et al. [7] & 1998 & 188 & $184(98 \%)$ \\
Smith et al. [21] & 2001 & 128 & $124(97 \%)$ \\
Schoonjans and Brem [22] & 2001 & 243 & $234(96 \%)$ \\
Bolívar et al. [23] & 2005 & 118 & $114(97 \%)$ \\
Crystal et al. [24] & 2005 & 323 & $311(96 \%)$ \\
Dillon et al. [25] & 2005 & 769 & $756(98 \%)$ \\
Murta de Lucena et al. [17] & 2007 & 101 & $95(94 \%)$ \\
Schueller et al. [10] & 2008 & 709 & $698(98.5 \%)$ \\
Youk et al. [26] & 2010 & 1,982 & $1,932(97.5 \%)$ \\
TOTAL & & 4,653 & $4,538(97.5 \%)$ \\
\hline
\end{tabular}


biopsy (B4 or B5). Adequate treatment should be performed.

- Discordant malignancy: a radiologically benign lesion (BI-RADS 2 or 3 ) is finally diagnosed as histologically malignant after core biopsy (B4 or B5). Adequate treatment should be performed.

- Concordant benignity: the radiological findings are benign or low-intermediate suspicious (BI-RADS 2, 3, $4 \mathrm{a}, 4 \mathrm{~b}$ ), and histological features are benign (B1 or B2 categories). An adequate radiological-pathological correlation should be established, and imaging follow-up should be offered to avoid delayed false-negative results. Exceptionally, some of these lesions can be surgically or percutaneously excised because of patient anxiety, patient decision or physician preference.

- Discordant benignity: a radiologically malignant lesion (BI-RADS category $4 \mathrm{c}$ or 5 ) is proved to be benign after core biopsy. In this case, both the imaging and the pathological findings should be reviewed again. It is imperative to find a diagnosis; therefore, a new percutaneous biopsy (including vacuum-assisted breast biopsy) or a surgical removal can be offered.

- Borderline findings: atypical ductal hyperplasia, lobular neoplasm, radial scar, papillary lesion and phyllodes tumour, are classified as B3 pathological results and usually require the removal of the whole lesion. It has been demonstrated that the rates of underestimation decrease as the number and calibre of samples increase [29]. In cases of atypical ductal hyperplasia or radial scar with atypia, a surgical biopsy is probably the best option because it is possible to find histological features of ductal carcinoma in situ or even invasive carcinoma in the surrounding tissue.

\section{Complications}

The complications of ultrasound CNB are infrequent and not significant. Both haematomas and infections are very rare, accounting for less than $1 / 1,000$ biopsies [5], being similar to the complications of other percutaneous biopsy devices. The possibility of pneumothorax exists [30], but it is very rare using the free-hand technique and a horizontal approach. Patients should be informed about the possible complications of the technique.

One complication of all percutaneous biopsies is epithelial displacement. It was first described by Harter et al. [31] in 1992. In 1999, Diaz et al. [32] concluded that epithelial displacement was seen in up to $37 \%$ of all biopsies. However, the displaced cells did not seem to be viable. Later, in 2002, Chen et al. [33] compared the recurrences after percutaneous biopsies vs surgical biopsies in patients with breast-conserving therapy, and found no significant differences in recurrence rates. Thus, whatever the method of biopsy, the recurrence rate was similar.

\section{Conclusion}

All BI-RADS 4 and BI-RADS 5 lesions, and some BIRADS 3 ones, should be percutaneously punctured, and in cases with benign results, surgery can be avoided if there is a good radiological-pathological correlation and no borderline result is obtained. Ultrasound CNB is a well-known, safe and accurate technique that is currently considered the elective method, whereas stereotaxy and MRI should be reserved for lesions that are not clearly seen on ultrasound. Complications are infrequent and not serious.

For these reasons, we would encourage all breast radiologists to gain plenty of experience of this technique.

\section{References}

1. Liberman L (2000) Percutaneous imaging-guided core breast biopsy: state of the art at the millennium. AJR Am J Roentgenol 174:1191-1199

2. Parker SH, Lovin JD, Jobe WE, Luethke JM, Hopper KD, Yakes WF, Burke BJ (1990) Stereotactic breast biopsy with a biopsy gun. Radiology 176:741-747

3. Liberman L (2002) Percutaneous image-guided core breast biopsy. Radiol Clin North Am 40:483-500

4. Parker SH (1994) Percutaneous large core breast biopsy. Cancer 74:256-262

5. Parker SH, Burbank JRJ et al (1994) Percutaneous large-core breast biopsy: a multi-institutional study. Radiology 193:359-364

6. Schueller G, Schueller-Weidekamm C, Helbich TH (2008) Accuracy of ultrasound-guided, large-core needle breast biopsy. Eur Radiol 18:1761-1773

7. Schulz-Wendtland R, Krämer S, Lang N, Bautz W (1998) Ultrasonic guided microbiopsy in mammary diagnosis: indications, technique and results. Anticancer Res 18:2145-2146

8. Liberman L, Feng TL, Dershaw DD, Morris EA, Abramson AF (1998) US-guided core breast biopsy: use and cost-effectiveness. Radiology 208:717-723

9. Parker SH, Jobe WE, Dennis MA, Stavros AT, Johnson KK, Yakes WF, Truell JE, Price JG, Kortz AB, Clark DG (1993) US-guided automated large-core breast biopsy. Radiology 187:507-511

10. Schueller G, Jaromi S, Ponhold L, Fuchsjaeger M, Memarsadeghi M, Rudas M, Weber M, Liberman L, Helbich TH (2008) USguided 14-gauge core-needle breast biopsy: results of a validation study in 1352 cases. Radiology 248:406-413

11. Somerville P, Seifert PJ, Destounis SV, Murphy PF, Young W (2008) Anticoagulation and bleeding risk after core needle biopsy. AJR Am J Roentgenol 191:1194-1197

12. Roberts JG, Preece PE, Bolton PM, Baum M, Hughes LE (1975) The 'tru-cut' biopsy in breast cancer. Clin Oncol 1:297-303

13. Liberman L, Ernberg LA, Heerdt A, Zakowski MF, Morris EA, La Trenta LR, Abramson AF, Dershaw DD (2000) Palpable breast masses: is there a role for percutaneous imaging-guided core biopsy? AJR Am J Roentgenol 175:779-787 
14. Fornage BD, Sneige N, Ross MI, Mirza AN, Kuerer HM, Edeiken BS, Ames FC, Newman LA, Babiera GV, Singletary SE (2004) Small $(<$ or $=2-\mathrm{cm})$ breast cancer treated with US-guided radiofrequency ablation: feasibility study. Radiology 231:215-224

15. Roubidoux MA, Sabel MS, Bailey JE, Kleer CG, Klein KA, Helvie MA (2004) Small $(<2.0-\mathrm{cm})$ breast cancers: mammographic and US findings at US-guided cryoablation - initial experience. Radiology 233:857-867

16. Van Esser S, van den Bosch MA, van Diest PJ, Mali WT, Borel Rinkes IH, van Hillegersberg R (2007) Minimally invasive ablative therapies for invasive breast carcinomas: an overview of current literature. World J Surg 31:2284-2292

17. Fishman JE, Milikowski C, Ramsinghani R, Velasquez MV, Aviram G (2003) US-guided core-needle biopsy of the breast: how many specimens are necessary? Radiology 226:779-782

18. Murta De Lucena CE, Dos Santos JL, Resende CA, Do Amaral VF, Barra AA, Pena JH (2007) Ultrasound-guided core needle biopsy of breast masses: how many cores are necessary to diagnose cancer? J Clin Ultrasound 35:363-367

19. Kim MJ, Kim EK, Lee JY et al (2007) Breast lesions with imaging-histologic discordance during US-guided $14 \mathrm{G}$ automated core biopsy: can the directional vacuum-assisted removal replace the surgical excision? Initial findings. Eur Radiol 17:2376-2383

20. Philpotts LE, Hooley RJ, Lee CH (2003) Comparison of automated versus vacuum-assisted biopsy methods for sonographically guided core biopsy of the breast. AJR Am J Roentgenol 180:347-351

21. Smith DN, Rosenfield Darling ML, Meyer JE et al (2001) The utility of ultrasonographically guided large-core needle biopsies. J Ultrasound Med 20:43-49

22. Schoonjans JM, Brem RF (2001) Fourteen-gauge ultrasonographically guided large-core needle biopsy of breast masses. J Ultrasound Med 20:967-972

23. Bolívar AV, Alonso-Bartolomé P, García EO, Ayensa FG (2005) Ultrasound-guided core needle biopsy of non-palpable breast lesions: a prospective analysis in 204 cases. Acta Radiol 46:690 695

24. Crystal P, Korets M, Shcharynsky S, Makarov V, Strano S (2005) Accuracy of sonographically guided 14-gauge core-needle biopsy: results of 715 consecutive breast biopsies with at least 2-year follow-up of benign lesions. J Clin Ultrasound 33:47-52

25. Dillon MF, Hill AD, Quinn CM, O'Doherty A, McDermott EW, O'Higgins N (2005) The accuracy of ultrasound, stereotactic, and clinical core biopsies in the diagnosis of breast cancer, with an analysis of false-negative cases. Ann Surg 242:701-707

26. Youk JH, Kim EK, Kim MJ, Kwak JY, Son EJ (2010) Analysis of false-negative results after US-guided 14-gauge core needle breast biopsy. Eur Radiol 20:782-789

27. Youk JH, Kim EK, Kim MJ, Lee JY, Oh KK (2007) Missed breast cancers at US-guided core needle biopsy: how to reduce them. Radiographics 27:79-94

28. Parikh J, Tickman R (2005) Image-guided tissue sampling: where radiology meets pathology. Breast J 11:403-409

29. Jackman RJ, Burbank F, Parker SH, Evans WP 3rd, Lechner MC, Richardson TR, Tocino I, Wray AB (1997) Atypical ductal hyperplasia diagnosed at stereotactic breast biopsy: improved reliability with 14-gauge, directional, vacuum-assisted biopsy. Radiology 204:485-488

30. Meyer JE, Smith DN, Lester SC, Kaelin C, Di Piro PJ, Denison CM, Christian RL, Harvey SC, Selland DL, Durfee SM (1999) Large-core needle biopsy of nonpalpable breast lesions. JAMA 281:1638-1641

31. Harter LP, Curtis JS, Ponto G, Craig PH (1992) Malignant seeding of the needle track during stereotaxic core needle breast biopsy. Radiology 185:713-714

32. Diaz LK, Wiley EL, Venta LA (1999) Are malignant cells displaced by large-gauge needle core biopsy of the breast? AJR Am J Roentgenol 173:1303-1313

33. Chen AM, Haffty BG, Lee CH (2002) Local recurrence of breast cancer after breast conservation therapy in patients examined by means of stereotactic core needle biopsy. Radiology 225:707-712 